Journal of Money and Economy

Vol. 16, No. 2, Spring 2021

pp. $165-186$

DOI: $10.29252 /$ jme.16.2.165

Original Research Article

\title{
Estimation of Value at Risk (VaR) Based On Lévy- GARCH Models: Evidence from Tehran Stock Exchange
}

\section{Hossein Amiri* \\ Seyede Mohadese Mousavi ${ }^{\ddagger}$}

\author{
Mahmood Najafi Nejad ${ }^{\dagger}$
}

Received: 20 Apr $2021 \quad$ Approved: 29 Jan 2022

This paper aims to estimate the Value-at-Risk (VaR) using GARCH type models with improved return distribution. Value at Risk $(\mathrm{VaR})$ is an essential benchmark for measuring the risk of financial markets quantitatively. The parametric method, historical simulation, and Monte Carlo simulation have been proposed in several financial mathematics and engineering studies to calculate $\mathrm{VaR}$, that each of them has some limitations. Therefore, these methods are not recommended in the case of complications in financial modeling since they require considering a series of assumptions, such as symmetric distributions in return on assets. Because the stock exchange data in the present study are skewed, asymmetric distributions along with symmetric distributions have been used for estimating VaR in this study. In this paper, the performance of fifteen $\mathrm{VaR}$ models with a compound of three conditional volatility characteristics including GARCH, APARCH and GJR and five distributional assumptions (normal, Student's t, skewed Student's t and two different Lévy distributions, include normal-inverse Gaussian (NIG) and generalized hyperbolic (GHyp)) for return innovations are investigated in the chemical, base metals, automobile, and cement industries. To do so, daily data from of Tehran Stock Exchange are used from 2013 to 2020 . The results show that the GJR model with NIG distribution is more accurate than other models. According to the industry index loss function, the highest and lowest risks are related to the automotive and cement industries.

Keywords: Lévy Distribution, Value at Risk (VaR), GARCH Model, Risk Management.

JEL Classification: D51, D81, G32, L11.

\footnotetext{
*Faculty of Economics, Kharazmi University, Tehran, Iran; h.amiri@khu.ac.ir (Corresponding Author)

${ }^{\dagger}$ Faculty of Economics, Kharazmi University, Tehran, Iran; mahmoodnajafi24@gmail.com

† Faculty of Economics, Kharazmi University, Tehran, Iran; mosavi8145@gmail.com
} 


\section{Introduction}

Many experimental studies have been conducted to predict stock price volatility; however, there is no theoretical consensus on the best model. For example, the variance of the rate of return is controverted as a criterion to measure asset risk. In other words, when the distribution of return on assets (ROA) is not symmetric, the variance cannot accurately represent asset risk (Salah et al., 2018). In this case, the criterion that measures adverse risk will perform better. Changes in price, economic regulations, and other factors affecting the market supply and demand are the main reasons for uncertainty and risk (Fan et al., 2008). Data skewness and elongation are two statistical tests to assess the frequency of data scatter and check the distribution's normality. In statistical science, skewness is a measure of the symmetry or asymmetry of a distribution function. The skewness is positive for an asymmetric distribution with skewness towards higher values and the skewness value is negative for an asymmetric distribution with elongation towards smaller values. The skewness is zero for a perfectly symmetric distribution. Kurtosis represents the height of a distribution. In other words, elongation is a measure of the curve's height at the maximum point. Positive elongation means that the desired distribution peak is higher than the normal distribution and negative elongation indicates that the peak is lower than the normal distribution. For example, in the t distribution where the data scatter is greater than the normal distribution, the curve's height is shorter than the normal curve. Skewness is used to test the normality of the data. The data distribution elongation simply refers to the same height of the data distribution. The higher the probability density function of the peak and the wider the tail, or the wider the tail, the higher the elongation index for it. In the present study, this issue has been addressed in the descriptive statistics section of the data. It is one of the signs of the superiority of asymmetric distributions (Levy) over symmetric distributions.

One of the most important criteria used in financial markets is the value at risk. Baumol (1963) first proposed the concept of value at risk, but it has been widely used to measure risk since the early 1990s. By definition, VaR is the maximum loss. A decrease in the portfolio value for a given period in the future does not exceed a certain degree of confidence (Alexander and Baptista, 2003). In other words, VaR indicates how much the value of an asset is at risk regarding $\mathrm{x} \%$ probability over a specified time horizon (Duffie and Pan, 1997). Determining the amount of venture capital brings the investors the confidence to meet their obligations by maintaining the calculated venture 
capital index, even if the maximum loss is realized (Gründl and Gal, 2017). Accordingly, it has been proposed as a criterion to determine the capital adequacy ratio in money markets and financial institutions (Braione and Scholtes, 2016).

Financial analysts tend to estimate the conditional variance of stock prices accurately. Since the GARCH models can predict conditional variance, they can also calculate an asset's risk in the long term (Bollerslev et al., 1992; Palm, 1996). The goal is to model the risk correctly and accurately. On the other hand, financial data is usually heavy-handed with a certain kind of long-term dependency; therefore, considering a normal distribution is not suitable (Costa et al., 2005). For this reason, we also consider the Lévy distribution for the data set. Lévy processes are among the simplest Markov jump models, suitable for consistent results with financial market data (Tankov, 2010). These processes are infinitely distributable and capable of displaying additional skewness and kurtosis.

On the other hand, by applying a random time change to the Lévy processes' components, the time-changed Lévy process emerges (Geman et al., 2001). Another process is subordination, which means constructing a timechanged Lévy process using another increasing Lévy process (Luciano and Semeraro, 2010). This study used Lévy distribution and GARCH family models to estimate risk in different stock industries.

The main purpose of the study is to determine a model that is capable of estimating the risk value of stocks of listed companies in the Tehran Stock Exchange. In fact, in this study, we aim to explain the modeling of value at risk based on the parametric method (GARCH family) and compare the value at risk based on GARCH models under Lévy distribution and other distribution. The present study uses Lévy distribution as a statistical tool for advanced risk modeling. In examining the specification of GARCH models, conditional volatility models and VaR were used under different error distribution hypotheses in the stock market. In the volatility fluctuation models group, standard $\mathrm{GARCH}^{1}$, $\mathrm{APARCH}^{2}, \mathrm{GJR}^{3}$ models, normal distributions, Student's t, skewed Student's t, Lévy distributions (including normal-inverse Gauss distribution (NIG)), and the generalized hyperbolic distribution (GHyp) were used. The statistical sample is the indicators of the chemical industry. In the article, we use stock price indices of chemical ${ }^{4}$, base

\footnotetext{
${ }^{1}$ Generalized Autoregressive Conditional Heteroscedasticity

${ }^{2}$ Asymmetric Power Autoregressive Conditional Heteroscedastic

${ }^{3}$ Glosten, Jagannathan and Runkle

${ }^{4}$ All companies that produce or invest in chemical products are classified in this group
} 
metals, automotive, and cement industries in Tehran Stock Exchange from 2013 to 2020 with daily frequency.

The remainder of the study is organized as follows: Section 2 reviews the existing literature from the theoretical and empirical perspectives. It is followed by the methodology in Section 3. Section 4 discusses the estimation results, and finally, Section 5 deals with conclusions and suggestions.

\section{Literature Review}

\subsection{Theoretical Review}

The term "Value at Risk" (VaR) was not added to the financial literature until the early 1990s; however, VaR was first considered in 1922 when the New York Stock Exchange informally tested the capital of the listed companies (Glyn, 2002).

Market risk is defined uncertainty in a financial institution's trading portfolio as a result of market condition changes, including asset prices, interest rates, market fluctuations, and market liquidity (Yildirak and Ekinci, 2013). Market risk arises when a financial institution is actively engaged in trading assets, liabilities, and derivatives, not when it maintains such items for long-term investing, financing, and hedging. VaR is the most effective method that is used for market risk measurement.

\subsection{VaR and Volatility Specifications}

The VaR concept has emerged as the most prominent measure of downside market risk. It places an upper frontier on losses at a given confidence level over a given forecast horizon. Thus, assuming that the VaR model is correct, realized losses will exceed the VaR sill with only a small target possibility $\alpha$, which typically is selected between $1 \%$ and $5 \%$. More specifically, conditional on the information until time $t-h$, the $\mathrm{VaR}$ (for a long position) at time $\mathrm{t}$ of one unit of investment is the $\alpha$-quantile of the conditional return distribution, that is:

$$
\operatorname{Var}_{t}=q_{\alpha}\left(r_{t} \mid F_{t-1}\right)=\inf \left\{x \in R \mid P\left(r_{t} \leq x \mid F_{t-1}\right) \geq \alpha\right\}
$$

Where $q_{\alpha}$ denotes the quantile function, $r_{t}$ is the index return in period t, and $F_{t-1}$ designates the information existent at date $\mathrm{t}-1$. When the envisage returns, $r_{t}$, are assumed to follow a location-scale distribution, they are 
regarded as a function of an innovation process, $\varepsilon_{t}$, conditional on a given $F_{t-1}$ and measurable parameter $a_{t}$. Specifically:

$$
\begin{aligned}
& r_{t}=a_{t}+\varepsilon_{t} \\
& \varepsilon_{t}=\sigma_{t} z_{t}
\end{aligned}
$$

Where $a_{t}$ and $\sigma_{t}$ are the location and scale ingredients, respectively. $z_{t}$ is an independent and identically distributed (i.i.d.) random variable that follows a zero-mean, unit-variance probability density function. Without loss of generality, we assume a constant conditional location $a_{t}=a_{0}$.

Our study considers the modeling and computation of VaR for portfolio managers who have taken either a long position or a short position. In the former case, the risk comes from a drop in the prices of assets, while in the latter case, the trader will incur a loss when the asset price increases. To fully consider risk presentation arising from both long and short trading positions, one needs accurate modeling of the left and the right tails of the returns distribution. The one-day-ahead VaR forecast for long and short trading positions (i.e., $\operatorname{VaR}_{L, t}$ and $\operatorname{VaR}_{s, t}$ ) at time $\mathrm{t}$ can be written, respectively, as follows:

$$
\begin{aligned}
\mathrm{VaR}_{L, t} & =\hat{a_{0}}+q_{\alpha}(\mathrm{z}) \hat{\sigma_{t}} \\
\mathrm{VaR}_{s, t} & =\hat{a}_{0}+q_{1-\alpha}(\mathrm{z}) \hat{\sigma}_{t}
\end{aligned}
$$

Where $q_{\alpha}(z)$ and $q_{1-\alpha}(z)$ denote the left and right quantile tacit by $f_{z}$ at the importance level of $\alpha$ and 1- $\alpha$, respectively. $\hat{\alpha}_{0}$ and $\hat{\sigma}_{0}$ refer to the estimated/forecasted conditional place and scale of the index returns, respectively. While the place parameter is of little relevance for short holding periods, the key issue in VaR modeling is the specification of the conditional scale. In light of the stylized facts of financial returns such as volatility clustering, asymmetry, and long memory, the GARCH-type models have become largely beloved for describing the time-varying conditional volatility of financial returns. In the following, we present the standard GARCH model, the fractionally integrated GARCH model, and the GJR model (Abad et al., 2014). 
The VaR is calculated based on the confidence level if the return on asset is the same as in Fig 1.

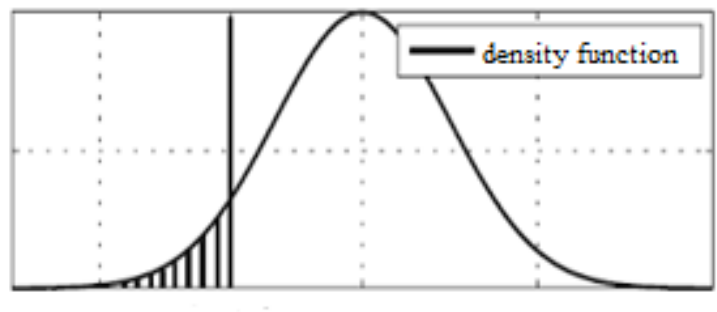

value at risk

Figure 1. Estimation of Value at Risk.

As shown in figure 1, the sequence-wide distribution function seems to be a better choice to plot the probability distribution function of the asset return that is likely to increase or decrease significantly in its rate of return. Therefore, it may no longer be reasonable to estimate GARCH family models using the normal distribution-based probability function and other distribution functions with smaller kurtosis.

\subsection{Empirical Review}

The history of fluctuations in financial markets, such as the conversion of the fixed exchange rate system to the floating exchange rate regime in 1971, the oil price shock in 1973, the fall of US stocks on Black Monday in 1987, the bursting of the Japanese stock price bubble in 1989, the Southeast Asian financial crisis in 1997, and the closure of financial markets and the devaluation of US stocks on September 11, 2001, are reasons why financial institutions need to be managed and taken into account (Greenwald et al., 2014). Moreover, the emergence of the 2007-2008 financial market crisis has already highlighted the importance of risk management and accurate risk measurement.

Fallahpour et al. (2015) using symmetric and asymmetric conditional variance heterogeneity models in the gold and oil market concluded that the estimation of conditional risk value in the oil market is more valid than in the gold market. Sadeghi and Behboodi (2016) studied that the extreme value theory approach is better in modeling US dollar fluctuations than the other models, whose computational assumptions were based on normality. Braione 
and Scholtes (2016) showed that heavy-tailed and skewed distributions have better performance in GARCH and MGARCH models. Gaye Gencer (2016) showed that FIAPARCH models were the best fit for all markets under student's t skewed distribution assumption.

Aghamohammadi and Sojoudi (2017) found that the composite quantile regression is more accurate in estimating $\mathrm{VaR}$ than the least square method and quantile method. Nilsson (2017) concluded that the best model for predicting fluctuations is the APARCH model. Li (2017) showed that the conditional EVT performs better than the GARCH model under general error distribution (GED); on the other hand, the GARCH-based model performs better in predicting risk value.

Ebrahimi et al. (2017) concluded that t-distribution and risk factor as a random variable has led to more conservative estimates for VaR. Francq and Zakoïan (2018) presented a dynamic semi-parametric and multivariate model. The results indicated the usefulness and feasibility of the research approach. Zhu et al. (2019) showed that in comparison with the traditional VaR, the EMD-VaR model could effectively reduce the effects of heterogeneous environments (such as the effects of extreme events) and achieve a more accurate measurement of the overall risk in the European carbon market.

Numerous studies have examined the empirical behavior of ROA in financial markets worldwide and rejected the hypothesis indicating the normal distribution of ROA. A review of the research background revealed that financial asset management and pricing methods need appropriate modeling to distribute returns on financial assets. However, the distribution of returns in traditional asset pricing theories is normal. This study addresses this research gap using Asymmetric distributions (Lévy processes distributions).

\section{Data and Methodology}

To fit GARCH, APARCH, GJR-GARCH econometric models with symmetric distributions (normal, Student's t, skewed Student's t) and Lévy distributions (normal-inverse Gaussian, generalized hyperbolic), Oxmetrics, Eviews, and Rstudio software were used to analyze the data.

\subsection{Introducing the Models}

\subsubsection{GARCH Model}

The GARCH model was introduced in 1986 (Bollerslev, 1986). Its simple mode is: 
$\sigma_{t}^{2}=\alpha_{0}+\alpha_{1} u_{t-1}^{2}+\beta \sigma_{t-1}^{2}$

\subsubsection{GJR Model}

The GJR model is the simplest type of asymmetric GARCH model (Zakoian, 1994). In pecuniary markets, mostly the downward movements in the market lead to higher fluctuations than upward movements; this incommensurability can be modeled using the GJR model, in which the effect of $u_{t-1}^{2}$ is dependent on the shock signal:

$\sigma_{t}^{2}=\alpha_{0}+\beta_{1} u_{t-1}^{2}+\beta_{2} \sigma_{t-1}^{2}+\beta_{3} u_{t-1}^{2} I_{t-1}$

\subsubsection{APARCH Model}

The APARCH model or asymmetric power ARCH model is another nonlinear and asymmetric model introduced by Ding et al. (1993). This model can express elongated tails, excessive kurtosis, and leverage effects. Instead of conditional variance of $\sigma_{t}^{2} \mathrm{GARCH}$, in this model, the long-term memory term $\sigma_{t}^{\delta}$ is introduced. The general structure of the model is as follows:

$$
\sigma_{t}^{\delta}=\omega+\alpha\left(\left|\varepsilon_{t-1}\right|-\gamma \varepsilon_{t-1}\right)^{\delta}+\beta \sigma_{t-1}^{\delta}
$$

\subsection{Probability Distribution Function}

\subsubsection{Lévy Process}

The Lévy process is a continuous random process in which the random component is the same as the discrete state of an IID process (Leonenko et al., 2014). The simplest random process is a Brownian motion formed based on the normal distribution. The introduction of the Lévy process has led to greater flexibility in modeling.

A Lévy process $Y=\left\{x_{t}, t \geq 0\right\}$ is highly correlated with the $\mathrm{F}$ distribution. The Lévy formula provides a general form of the characteristic $\mathrm{F}$ function:

$\varphi F(u)=\exp \left(i u \mu-\frac{1}{2} u^{2} \delta^{2}+\int_{R 0}\left(e^{i u x}-1-\left.i u x\right|_{|x|_{\mid 1}}\right) K(X) d x\right)$

In the above model, $\mu \in R$ and $\sigma^{2}>0$ is the dispersion component of the model. Also, $K(x)$ indicates the density of Lévy. The above three components determine the distribution of the process.

\subsubsection{Normal-Inverse Gaussian Distribution (NIG)}

The NIG density function of a random variable is as follows: 


$$
f_{N I G}(z: \mu, \alpha, \beta, \delta)=\frac{\alpha \delta K_{t}\left(\alpha \sqrt{\delta^{2}+(z-\mu}\right)^{2}}{\pi \sqrt{\delta^{2}+(z-\mu)^{2}}} e^{\delta \sqrt{\alpha^{2}-\beta^{2}+\beta(z-\mu)}}
$$

Where $\mu \in R, 0 \leq|\beta| \leq \alpha$ and $\sigma>0 . \mathrm{K}_{\mathrm{t}}$ expresses the function of Bessel. In the above relation, $\alpha$ controls kurtosis and $\beta$ asymmetry of the distribution. The parameters $\delta$ and $\mu$ specify the scale and the status of the respectively, distribution. The attractiveness of the (NIG) distribution is in modeling distributions with abnormal kurtosis and skewness.

\subsubsection{Generalized Hyperbolic Distribution (GHyp)}

The generalized hyperbolic distribution $(\mathrm{GH})$ was first used by BarndorffNielsen (1977) as a model for dust particle distribution caused by wind blowing. The density of the generalized hyperbolic distribution is as follows:

$$
\begin{aligned}
& f_{G H}(X)=a(\lambda, \alpha, \beta, \delta, \mu)\left(\delta^{2}+(X-\mu)^{2}\right)^{\left(\frac{\lambda-\frac{1}{2}}{2}\right)} e^{\beta(x-\mu)} \\
& \times K_{\lambda-\frac{1}{2}}\left(\alpha \sqrt{\delta^{2}+(X-\mu)^{2}}\right)
\end{aligned}
$$

Where $X \in R$ and:

$$
a(\lambda, \alpha, \beta, \delta, \mu)=\frac{\left(\alpha^{2}-\beta^{2}\right)^{\frac{\lambda}{2}}}{\sqrt{2 \pi}^{\lambda \frac{1}{2}} \delta^{\lambda} K_{\lambda}\left(\delta \sqrt{\alpha^{2}-\beta^{2}}\right)}
$$

And $k v$ is the modified Bessel function of the third type and $v$ order, which is as in the following relation:

$$
K_{v}(z)=\frac{1}{2} \int_{0}^{\infty} y^{v-1} \exp \left(-\frac{1}{2} z\left(y+y^{-1}\right)\right) d y
$$

The range of generalized hyperbolic distribution parameters is as follows:

$$
\lambda, \mu \in R, \quad \delta, \alpha>0, \quad \alpha^{2}>\beta^{2}
$$

Distribution parameters have special meanings; $\lambda$ is a parameter that determines the shape of the distribution. For a fixed number of $\lambda$, $\alpha$ determines 
the weight of the tails. $\beta, \delta$ and $\mu$ are the skewness, scale, and location parameters, respectively. If $\beta=0$, then the generalized hyperbolic distribution is called symmetric generalized hyperbolic distribution.

\subsection{Backtesting and Normality Test}

\subsubsection{Jarque-Bera Test for Normality}

The Jarque-Bera test is used for the statistical inference to evaluate a good fit in the skewness and kurtosis of the sample data with a normal distribution (Bai and Ng, 2005). This test was first introduced by Jarque and Bera (1980). The function of the test samples is as follows:

$$
J B=\frac{N}{6}\left(S^{2}+\frac{1}{4} K-3\right)^{2}
$$

Where $N$ is the number of observations, $S$ is the skewness coefficient of the sample, and $K$ is the kurtosis coefficient of the sample.

\subsubsection{Backtesting}

$\mathrm{VaR}$ forecasting models require validation and performance evaluation. One of the methods to evaluate the performance of models is backtesting, which uses quantitative approaches to determine the conformity of the model predictions with its underlying assumptions. It also allows ranking different VaR estimation methods

\subsubsection{Kupiec Test}

In this study, the Kupiec test (unconditional coverage test) was used to estimate the accuracy of the models in determining the value at risk. This test is based on the maximum likelihood ratio test to determine the accuracy of different models in the given range (Kupiec, 1995). In this test, the number of violations of the predicted loss according to the model from the realized loss is considered a failure. In other words, if the loss predicted by the model becomes less than the realized loss, it is considered a failure (violation). If the realized loss is less than the predicted loss is assessed as a success. The likelihood-ratio ( $\mathrm{LR}_{\mathrm{POF}}$ ) test is used in the Kupiec test, which has a chi-square distribution. The formula for this test is as follows. 


$$
L R_{P O F}=2 \ln \left(\frac{V^{f}(1-V)^{T-f}}{a^{f}(1-a)^{T-f}}\right)
$$

where $f$ indicates the number of failures or the frequency of the times when the actual loss is greater than the loss estimated by $\mathrm{VaR}, T$ represents the number of predictions made by the VaR model, $V$ is the failure ratio, and $a$ is the error or significance level. After calculating the likelihood ratio, the test value is compared with the critical value. If the $L R$ value is greater than that of critical, the null hypothesis indicating the appropriateness of the VaR model at the desired significance level is confirmed. Accordingly, the model results are citable and appropriate.

\subsubsection{Christoffersen Test}

This test is the most well-known conditional coverage test proposed by Christoffersen (1998). In addition to the correct coverage rate, the Christoffersen (1998) test also examines the probability of dependence of today's return on the previous day. The Christoffersen (1998) test shows the independence of failures and successes from each other. In other words, it shows whether failures and successes are related to each other or not. The probability ratio is the relevant index of this test for independence, calculated by equation 15 . If the index calculated by this test becomes less than the critical chi-square of the index at the desired confidence level, the failures and successes are independent of each other.

$$
L R_{\text {ind }}=2 \ln \frac{\left(1-\hat{\pi}_{01}\right)^{T 00} \hat{\pi}_{01}^{T_{01}}\left(1-\hat{\pi}_{11}\right)^{T 10} \hat{\pi}_{11}^{T_{11}}}{\hat{\alpha}^{T_{1}}(1-\hat{\alpha})^{T 0}}
$$

By combining this independence index with the Kupiec test $\left(L R_{P O F}\right)$, a combined test is obtained to examine the characteristics of an appropriate VaR model, the correct failure rate, and the independence of exceptions or conditional coverage. The following equation expresses the combined test:

$$
L R_{C C}=L R_{\text {ind }}+L R_{P O F}
$$

\subsubsection{Lopez Test}

The Kupiec test statistically examines the accuracy of the value at risk models. If the accuracy of a model is not statistically rejected, the model will be acceptable. However, in many cases, we have several models, and backtesting 
confirms the accuracy of some of them. Obviously, at this time, choosing from the approved models is a problem facing risk management, and therefore, the Lopez test can be used. This test is calculated based on the loss function and is defined as:

$$
C= \begin{cases}1 & \text { if } \longrightarrow L_{t}>V a R_{t} \\ 0 & \text { if } \longrightarrow L_{t}>V a R_{t}\end{cases}
$$

According to the above equation, if the amount of real loss in a day is more than the amount of value at risk, it indicates the state of exception or the violation, and, the test function for that day is one, and otherwise, it equals zero. Accordingly, in the Lopez test, the number of violations or exceptions is calculated, and then the models are ranked. Any model with fewer failures has an appropriate ranking and is selected as the optimal model in estimating the value at risk (Lopez, 2001).

\subsubsection{Dynamic Quantile Regression Test}

This test was used by Engle and Manganelli (1999) to appraise the efficiency of models in measure VaR. This test is a more accurate and comprehensive version of Christoffersen (1998). The above test provides an index in which a variable takes a value of one in the case of an error in the VaR method and, otherwise, zero. On the other hand, Engle and Manganelli believed that in a well-proportioned and accurate VaR model, the deviations from its actual value in estimating $\mathrm{VaR}$ should be a sequence of numerical deviations, which are not serially correlated. Therefore, in the dynamic quantile regression test, serial correlation is tested, and the null hypothesis is that there is no correlation.

\section{Empirical Results}

The data used in this study consist of the returns of stock price indices of the base metals, automotive, cement, and chemical industries in the Tehran Stock Exchange from 2013 to 2020 with daily frequency. The results of Table 1 show that all four indices are stationary based on the Dickey-Fuller and Phillips-Perron tests. 
Table 1

Results of Unit Root Test

\begin{tabular}{llc}
\hline Variable & \multicolumn{1}{c}{ Test statistics } \\
\cline { 2 - 3 } & Dickey-Fuller & Phillips Prone \\
CH Index & $-19.80^{* * * *}$ & $-24.32^{* *}$ \\
CE Index & $-17.10^{* *}$ & $-22.41^{* * *}$ \\
AU Index & $-19.60^{*}$ & $-23.51^{*}$ \\
ME index & $-19.84^{* * *}$ & $-22.37^{* * *}$ \\
\hline
\end{tabular}

Note: $* * *, * *$ and $*$ denote significance at $1 \%, 5 \%$ and $10 \%$, respectively.

In Table 2, the descriptive statistics including mean, standard deviation, skewness, kurtosis coefficient, minimum, and maximum, and Jarque Bera for the return of stock price indices of chemical $(\mathrm{CH})$, base metals $(\mathrm{ME})$, automobile (AU), and cement (CE) industries are provided.

Table 2

Descriptive statistics of Variables

\begin{tabular}{lllll}
\hline & ME index & AU Index & CE Index & CH Index \\
\hline Mean & 0.0014 & 0.0016 & 0.0016 & 0.0014 \\
Standard & 0.013 & 0.020 & 0.012 & 0.011 \\
Deviation & & & & \\
Skewness & 0.68 & 0.25 & 0.66 & 0.62 \\
Kurtosis & 8.30 & 3.75 & 4.51 & 8.87 \\
Minimum & -0.08 & -0.06 & -0.04 & -0.06 \\
Maximum & 0.1 & 0.13 & 0.05 & 0.09 \\
Jarque Bera & 2143.61 & 58.74 & 290.99 & 2576.83 \\
\hline
\end{tabular}

As shown in Table 2, the average returns in all four industries' indices are positive. It also firmly rejects the Jarque Bera normality test. Skewness is positive for all four industry indicators. These features highlight the use of the VaR model for various distributions.

The results of estimating the indices of chemical, cement, automotive, and base metal industries using GARCH, GJR, and APARCH models with normal, Student's t, skewed Student's t, and Lévy (Ghyp and NIG) distributions are reported in Table 3. The parameters of GARCH, GJR, and APARCH models are significant under all symmetric and asymmetric distributions (For all distributions $\beta_{1}+\beta_{2}$ is approximately equal to 1 ).

The results of the Kupiec (LR) and Angel and Manganelli (DQ) tests are reported in Table 4 for all four industries in the short-term and long-term 
horizons. The Kupiec (LR) test show that almost all the estimations confirm the null hypothesis, indicating that the models are appropriate based on unconditional coverage. In modeling a time series, first one must ensure that the time series is stationary. In financial time series, ignorance of this point is usually due to the fact that there is no fixed level for returns. In the time series literature, such an anonymous time series is called a single-root anonymous time series, since the data is used daily, so it is necessary to test the existence of long-term memory to confirm the presence or absence of the test. There is also a single root.

Moreover, Angel and Manganelli's (DQ) tests are not rejected in the long run for most distributions (i.e., the assumption of no correlation has not been rejected). Therefore, these models are sufficient to estimate the value at risk (VaR) for all four industries. Among the models with long-term adequacy, the models with the lowest loss function were selected. GJR-GHyp and GJR-tskewed models with the loss function value of 0.0201, GJR-t-Student and GJR-NIG models with the loss function value of 0.0192, GARCH-NIG, GARCH-t-Student, GJR-NIG, and GJR-t-Student models with the loss function value of 0.0398, and GJR-NIG and GJR-t-Student models with the loss function value of 0.0261 are selected for $\mathrm{CH}, \mathrm{CE}, \mathrm{AU}$ and $\mathrm{ME}$ respectively. According to the loss function values of the industries' indices, the risk of the automotive industry is higher than in other industries, and the risk of the cement industry is lower than in other industries.

Christoffersen's test examines the independence of failures and successes cases. In other words, it shows that failures and successes are related to each other or not. If the $\mathrm{LR}_{\mathrm{CC}}$ statistic calculated by this test is greater than the critical value, it indicates that the failures and successes are independent of each other. Table 5 shows the Christoffersen test results for all four industries. For all four industries, the value of LR test statistics is greater than the critical value for all symmetric and asymmetric distributions and all models of GARCH, GJR, and APARCH. 


\section{Table 3}

Estimation of the chemical, cement, automotive, metal industry index models $(C H, C E, A U, M E)$

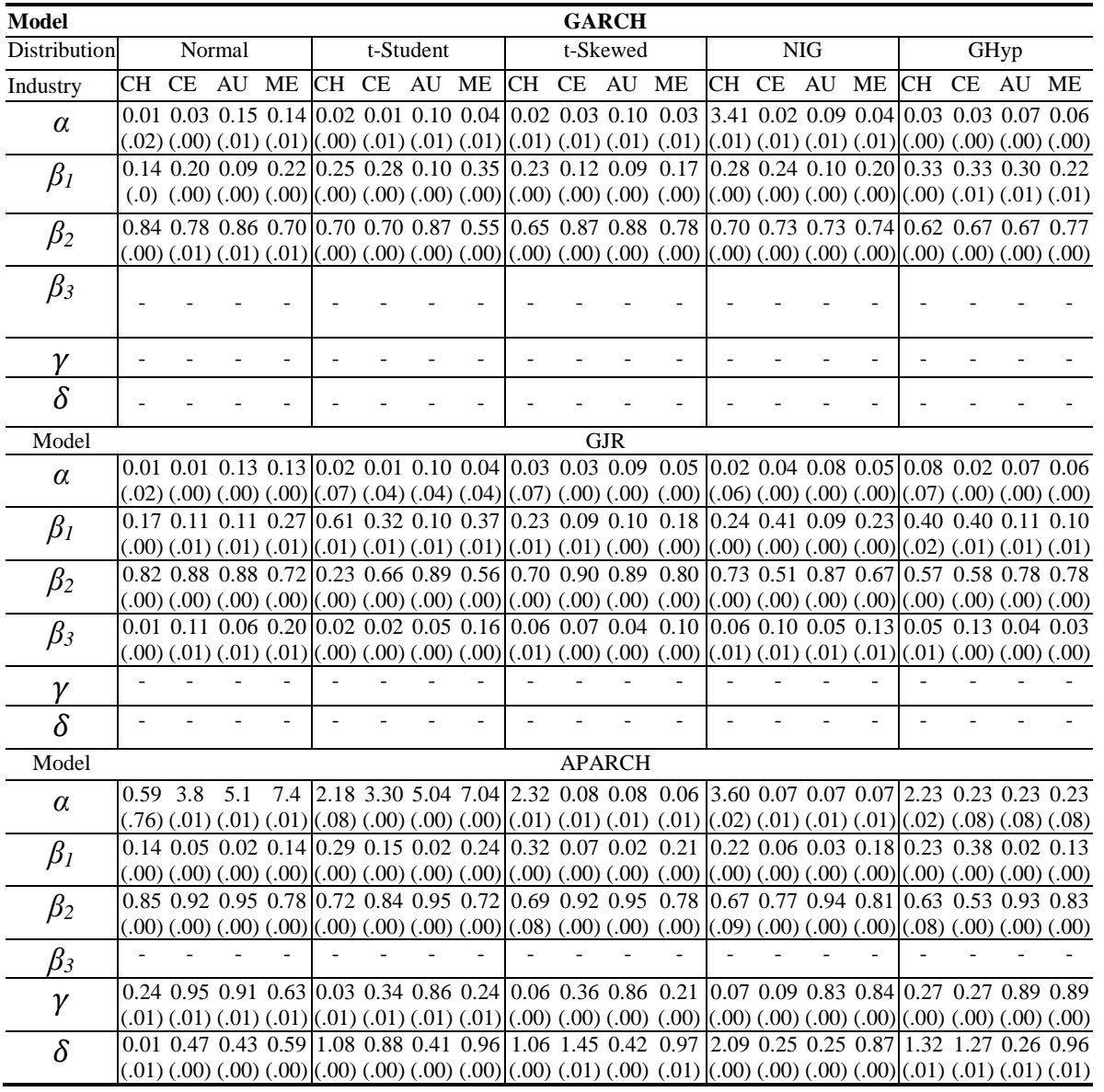


Table 4

Results of VaR backtesting for chemical, cement, automotive, metal industry index models (CH, CE, AU, ME)

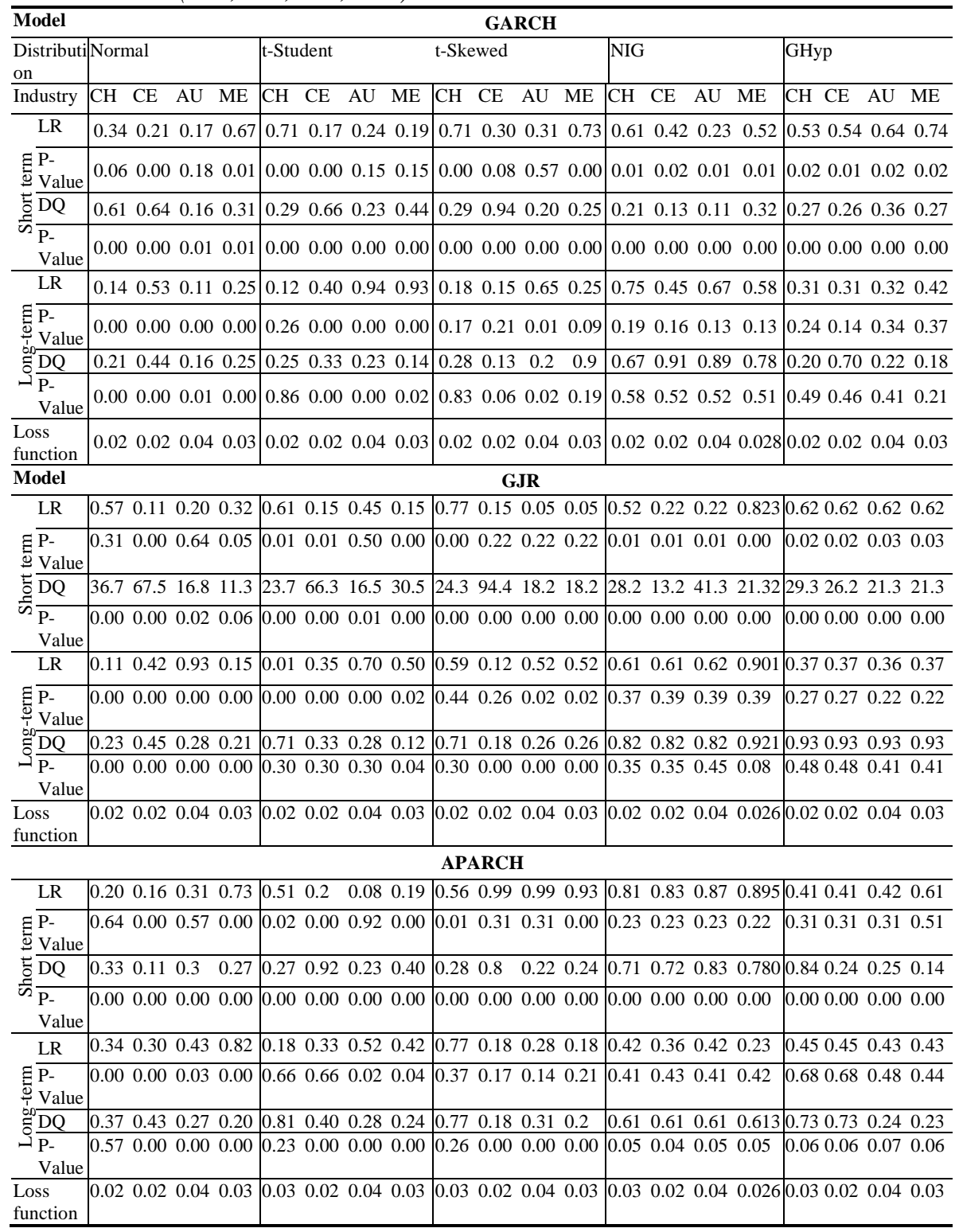




\section{Table 5}

Backtesting (Christoffersen) VaR results for chemical, cement, automotive, metal industry index models (CH, CE, $A U, M E)$

\begin{tabular}{|c|c|c|c|c|c|c|c|c|c|c|c|c|c|c|c|c|c|c|c|c|}
\hline Model & & & & & & & & & & GA & RCH & & & & & & & & & \\
\hline Distribution & & Nor & rmal & & & $\mathrm{t}-\mathrm{St}$ & udent & & & $\mathrm{t}-\mathrm{Sk}$ & ewed & & & NI & IG & & & & Нyp & \\
\hline Industry & $\mathrm{CH}$ & $\mathrm{CE}$ & $\mathrm{AU}$ & $\mathrm{ME}$ & $\mathrm{CH}$ & $\mathrm{CE}$ & $\mathrm{AU}$ & ME & $\mathrm{CH}$ & $\mathrm{CE}$ & $\mathrm{AU}$ & $\mathrm{ME}$ & $\mathrm{CH}$ & $\mathrm{CE}$ & $\mathrm{AU}$ & $\mathrm{ME}$ & $\mathrm{CH}$ & $\mathrm{CE}$ & $\mathrm{AU}$ & $\mathrm{ME}$ \\
\hline$\underset{\Xi}{\Xi} \mathrm{LR}_{\mathrm{CC}}$ & 0.23 & 0.37 & 0.13 & 30.42 & 0.70 & 0.24 & 0.54 & 0.34 & 0.60 & 0.55 & 0.35 & 50.32 & 0.73 & 0.40 & 0.47 & 0.63 & 0.41 & 10.13 & 30.13 & 30.22 \\
\hline है P-Value & 0.01 & 0.02 & 0.01 & 10.01 & 0.00 & 0.00 & 0.00 & 0.00 & 0.00 & 0.03 & 0.02 & 20.01 & 0.03 & 0.01 & 0.31 & 0.52 & 0.00 & 0.21 & 0.41 & 10.42 \\
\hline 芩 LRCC & 0.12 & 0.15 & 0.10 & 0.22 & 0.22 & 0.23 & 0.30 & 0.93 & 0.33 & 0.35 & 0.15 & 50.15 & 0.23 & 0.47 & 0.40 & 0.47 & 0.11 & 10.44 & +0.32 & 20.42 \\
\hline ב. P-Value & 0.00 & 0.00 & 0.00 & 0.00 & 0.16 & 0.02 & 0.02 & 0.02 & 0.43 & 0.10 & 0.02 & 20.12 & 0.28 & 0.57 & 0.51 & 0.31 & 0.29 & 90.21 & 0.31 & 10.21 \\
\hline 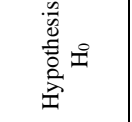 & 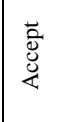 & 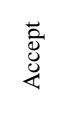 & $\begin{array}{l}\overrightarrow{0} \\
\stackrel{0}{0} \\
\stackrel{0}{*}\end{array}$ & 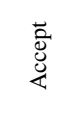 & $\begin{array}{l}\overrightarrow{0} \\
\stackrel{0}{0} \\
\dot{8}\end{array}$ & $\begin{array}{l}\overrightarrow{0} \\
\stackrel{0}{0} \\
\frac{u}{4}\end{array}$ & 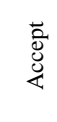 & $\begin{array}{l}\overrightarrow{0} \\
\stackrel{0}{0} \\
\stackrel{4}{4}\end{array}$ & 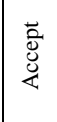 & $\begin{array}{l}\overrightarrow{0} \\
\stackrel{0}{0} \\
\dot{z}\end{array}$ & 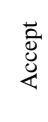 & 苍 & 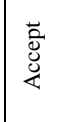 & $\begin{array}{l}\overrightarrow{0} \\
\stackrel{0}{0} \\
\ddot{z}\end{array}$ & $\begin{array}{l}\overrightarrow{0} \\
\stackrel{0}{4} \\
\stackrel{4}{4}\end{array}$ & $\begin{array}{l}\text { 苛 } \\
\text { 後 }\end{array}$ & $\begin{array}{l}\overrightarrow{0} \\
\stackrel{0}{0} \\
\frac{\pi}{4}\end{array}$ & 苨 & 苋 & 苛 \\
\hline Model & & & & & & & & & & G & JR & & & & & & & & & \\
\hline 志 $\mathrm{LR}_{\mathrm{CC}}$ & 0.12 & 0.33 & 0.23 & 30.93 & 0.41 & 0.60 & 0.30 & 0.10 & 0.33 & 0.42 & 0.42 & 20.22 & 0.62 & 0.64 & 0.62 & 20.42 & 7.60 & 0.13 & 30.12 & 20.31 \\
\hline है $\mathrm{P}$-Value & 0.03 & 0.01 & 0.00 & 0.01 & 0.00 & 0.20 & 0.40 & 0.30 & 0.00 & 0.02 & 0.00 & 0.00 & 0.00 & 0.15 & 0.25 & 0.35 & 0.00 & 0.21 & 0.81 & 10.51 \\
\hline$\underset{ \pm}{\Xi} \mathrm{LR}_{\mathrm{CC}}$ & 0.12 & 0.12 & 0.73 & 30.93 & 0.11 & 0.23 & 0.50 & 0.40 & 0.19 & 0.35 & 0.12 & 20.12 & 0.13 & 0.47 & 0.41 & 0.41 & 0.21 & 10.44 & +0.23 & 30.33 \\
\hline อิ P-Value & 0.00 & 0.00 & 0.00 & 0.00 & 0.40 & 0.02 & 0.05 & 0.04 & 0.20 & 0.10 & 0.01 & 10.00 & 0.15 & 0.57 & 0.02 & 20.01 & 0.58 & 80.21 & 0.31 & 0.41 \\
\hline $\begin{array}{l}\frac{n}{0} \\
\stackrel{0}{0} \\
\text { 总 }\end{array}$ & $\begin{array}{l}\overrightarrow{0} \\
\stackrel{0}{0} \\
\text { \& }\end{array}$ & $\begin{array}{l}\overrightarrow{0} \\
8 \\
\stackrel{8}{4}\end{array}$ & $\begin{array}{l}\overrightarrow{0} \\
\stackrel{0}{8} \\
\text { \& }\end{array}$ & 苛 & $\begin{array}{l}\overrightarrow{0} \\
\stackrel{0}{0} \\
\stackrel{4}{4}\end{array}$ & $\begin{array}{l}\overrightarrow{0} \\
\stackrel{0}{8} \\
\frac{8}{4}\end{array}$ & 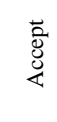 & $\begin{array}{l}\overrightarrow{0} \\
8 \\
\stackrel{0}{4}\end{array}$ & $\begin{array}{l}\overrightarrow{0} \\
\stackrel{0}{0} \\
\ddot{4}\end{array}$ & $\begin{array}{l}\overrightarrow{0} \\
\stackrel{8}{8} \\
\stackrel{4}{4}\end{array}$ & 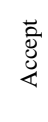 & 苛 & $\begin{array}{l}\overrightarrow{0} \\
\stackrel{0}{0} \\
\stackrel{u}{4}\end{array}$ & $\begin{array}{l}\overrightarrow{0} \\
\stackrel{0}{0} \\
\ddot{z}\end{array}$ & $\begin{array}{l}\overrightarrow{0} \\
\stackrel{0}{0} \\
\text { \& }\end{array}$ & 苍 & $\begin{array}{l}\overrightarrow{0} \\
\stackrel{0}{0} \\
\ddot{4}\end{array}$ & 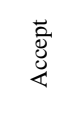 & 节 & 苍 \\
\hline Model & & & & & & & & & & APA & $\mathbf{R C H}$ & & & & & & & & & \\
\hline E $\mathrm{LR}_{\mathrm{CC}}$ & 0.21 & 0.33 & 0.33 & 30.23 & 0.42 & 0.21 & 0.21 & 0.22 & 0.33 & 0.17 & 0.17 & $\begin{array}{ll}70.17 \\
\end{array}$ & 0.27 & 0.37 & 0.25 & 0.22 & 0.51 & 10.23 & 30.43 & 30.40 \\
\hline Æ P-Value & 0.04 & 0.03 & 0.00 & 0.00 & 0.00 & 0.02 & 0.00 & 0.00 & 0.07 & 0.00 & 0.02 & 20.00 & 0.00 & 0.04 & 0.05 & 0.05 & 0.09 & 90.03 & 30.04 & 0.07 \\
\hline E LRCC & 0.13 & 0.42 & 0.22 & 20.22 & 0.32 & 0.21 & 0.11 & 0.11 & 0.27 & 0.17 & 0.21 & 10.37 & 0.12 & 0.22 & 0.19 & 0.23 & 0.24 & 40.03 & 30.33 & 30.43 \\
\hline อే P-Value & 0.47 & 0.00 & 0.01 & 10.00 & 0.33 & 0.00 & 0.00 & 0.00 & 0.56 & 0.00 & 0.00 & 0.00 & 0.15 & 0.01 & 0.03 & 0.03 & 0.75 & 50.03 & 30.03 & 0.05 \\
\hline 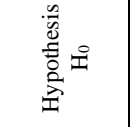 & 芯 & $\begin{array}{l}\overrightarrow{0} \\
\stackrel{0}{0} \\
\stackrel{4}{4}\end{array}$ & $\begin{array}{l}\overrightarrow{0} \\
\stackrel{0}{0} \\
\text { 岁 }\end{array}$ & $\begin{array}{l}\text { 苛 } \\
\text { 这 }\end{array}$ & 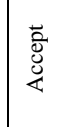 & 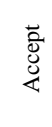 & 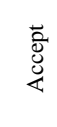 & $\begin{array}{l}\overrightarrow{0} \\
\stackrel{0}{0} \\
\ddot{4}\end{array}$ & 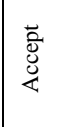 & 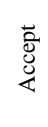 & $\begin{array}{l}\overrightarrow{0} \\
\stackrel{0}{0} \\
\stackrel{4}{4}\end{array}$ & 苍 & $\begin{array}{l}\overrightarrow{0} \\
\stackrel{0}{0} \\
\ddot{z}\end{array}$ & $\begin{array}{l}\overrightarrow{0} \\
\stackrel{0}{0} \\
\ddot{\&}\end{array}$ & 莺 & $\begin{array}{l}\overrightarrow{0} \\
\stackrel{0}{0} \\
\ddot{4}\end{array}$ & 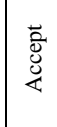 & 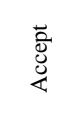 & 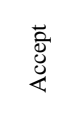 & 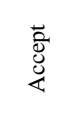 \\
\hline
\end{tabular}




\section{Conclusion and Discussions}

A review of recent studies on investment risk management and measurement in financial markets reveals that selecting the best criteria to calculate financial risk is particularly important. These studies indicate that the value-at-risk (VaR) measurement using different approaches has been welcomed by researchers in this field. Parametric and non-parametric techniques are among the risk calculation tools.

In this study, the VaR was estimated using GARCH, APARCH, and GJRGARCH models with normal, Student's t, skewed Student's t, normal-inverse Gaussian distribution (NIG)), and generalized hyperbolic (GHyp) distributions (the last two distributions are categorized as a Lévy distribution). The results show that the automotive industry risk is higher than other industries, and the risk of cement industries is lower than other industries.

The results of Kupiec, Christoffersen and Lopez tests show that GARCH models with asymmetric distributions are more reliable for measuring the market risk than non-parametric methods. There is also a significant difference between them in terms of predictive power. Therefore, it is suggested that portfolio managers in various industries, using the above models, estimate the maximum possible losses of their existing portfolio daily, weekly, or monthly and take appropriate measures to protect the portfolio from such losses.

Also, about investors, to select investment opportunities, and determine different stock compositions, pay attention to the small basis of measuring asset risk based on GARCH models with different distributions in the form of $\mathrm{VaR}$, and optimize their decisions in light of this basis.

The following are suggestions for researchers and scholars in line with the tangible research gap in studies:

The results of the test tables show that among the adequate models of each index, the lowest values of the loss function for the chemical, cement, automotive, and the basic metals industries' indices are 0.0201, 0.0192, 0.0398 , and 0.0261 respectively. In general, their loss (risk) in the automotive industry is higher than other industries, and the cement industry's risk is lower than other industries. In general, among the selected industries in this study, the risk of the automotive industry is higher than the base metals industry. The chemical industry is next, and the lowest risk is related to the cement industry. But this does not mean that, for example, the automotive industry is riskier than other stock exchange industries. Other industries should be weighed 
against the automotive industry to see the risk of other industries compared to this industry. Finally, choose a lower risk if the individual investor is riskaverse.

It is suggested that the measurement of value at risk using the GARCH model, with more asymmetric distributions (LVI) at different time intervals be examined and compared with the results of this study.

Since there is no limit on the type of assets in using the criterion of value at risk and we can use different types of assets, it is recommended to include other assets such as derivatives and ordinary shares.

\section{References}

Abad, P. S., \& Benito, C. López. (2014). A comprehensive review of Value at Risk methodologies. The Spanish Review of Financial Economics, 12(3), 15-32.

Aghamohammadi, A., \& Sojoudi, M. (2017). Estimating Value-at-Risk and Average Value-at-Risk Measures Using Composite quantile Regression. Journal of Statistical Sciences 10(6), 185-202.

Alexander, G. J., \& Baptista, A. M. (2003). Portfolio performance evaluation using value at risk. The Journal of Portfolio Management 29(6), 93-102.

Bai, J. S., \& N.g, (2005), Tests for skewness, kurtosis, and normality for time series data. Journal of Business \& Economic Statistics, 23(9), 49-60.

Barndorff-Nielsen, O., (1977). Exponentially decreasing distributions for the logarithm of particle size. Proceedings of the Royal Society of London. A. Mathematical and Physical Sciences, 353(3), 401-419.

Baumol, WJ., (1963). An expected gain-confidence limit criterion for portfolio selection. Management Science, 10(8), 174-182.

Bollerslev, T., (1986) Generalized autoregressive conditional heteroskedasticity. Journal of econometrics, 31(15), 307-327.

Bollerslev, T., R.Y. Chou, K.F. Kroner, (1992). ARCH modeling in finance: A review of the theory and empirical evidence. Journal of econometrics, 52(4), 5-59.

Braione, M., NK. Scholtes, (2016). Forecasting value-at-risk under different distributional assumptions. Econometrics, 4(4), 3-15

Cerqueti, R., M. Giacalone, R. Mattera, (2020). Skewed non-Gaussian GARCH models for cryptocurrencies volatility modeling. Information Sciences, 7(4), 4959.

Christoffersen, P.F., (1998). Evaluating interval forecasts. International economic review,9(13), 841-862.

Costa, M., G. Cavaliere, S. Iezzi. (2005). The role of the normal distribution in financial markets, New Developments in Classification and Data Analysis. Springer, pp. 343-350.

Ding, Z., C.W. Granger, R.F. Engle. (1993). A long memory property of stock market returns and a new model. Journal of empirical finance. 1(3), 83-106. 
Duffie, D., J. Pan, (1997). An overview of value at risk. Journal of derivatives 4(8), 7-49.

Ebrahimi, S.B., M. Aghaei, N. Mohebbi. (2017). Estimating Portfolio Value-at-Risk and Expected Shortfall by Possibility and Necessity Theory. Financial Research Journal. 19(6), 193-216.

Engle, R.F., S. Manganelli. (1999). CAViaR: conditional value at risk by quantile regression. National bureau of economic research.7(9), 35-45

Fallahpour, S., F. Rezvani, M. Rahimi. (2015). Estimating Conditional VaR Using Symmetric and Non-Symmetric Autoregressive Models in Old and Oil Markets. Financial Knowledge of Securities Analysis. 8(10), 1-18.

Fan, Y., Y.-J. Zhang, H.-T. Tsai, Y.-M. Wei. (2008). Estimating' Value at Risk'of crude oil price and its spillover effect using the GED-GARCH approach. Energy Economics. 30(12), 3156-3171.

Francq, C., J.-M. Zakoïan, (2018). Estimation risk for the VaR of portfolios driven by semi-parametric multivariate models. Journal of econometrics. 205(56), 381-401.

Geman, H., D.B. Madan, M. Yor. (2001). Time changes for Lévy processes. Mathematical Finance 11, 79-96.

Glyn, A., (2002). History of Value-at-Risk: 1922-1998. Working papers.

Greenwald, D.L., M. Lettau, S.C. Ludvigson, (2014). Origins of stock market fluctuations. National Bureau of Economic Research. 13(2), 12-45

Gründl, H., J. Gal, (2017). The evolution of insurer portfolio investment strategies for long-term investing. OECD Journal: Financial Market Trends. 16(12), 1-55.

Jarque, C.M., A.K. Bera, (1980). Efficient tests for normality, homoscedasticity and serial independence of regression residuals. Economics Letters. 6(12), 255-259.

Kupiec, P., (1995) Techniques for verifying the accuracy of risk measurement models. The J. of Derivatives. 12(25), 3-15.

Lechner, L. A., \& Ovaert, T. C. (2010). Value-at-risk: techniques to account for leptokurtosis and asymmetric behavior in returns distributions. Journal of Risk Finance, 11(5), 464-481.

Leonenko, N.N., M.M. Meerschaert, R.L. Schilling, A. Sikorskii, 2014, Correlation structure of time-changed Lévy processes. Communications in Applied and Industrial Mathematics. 6(18), 470-483.

Li, L., (2017). A Comparative Study of GARCH and EVT Model in Modeling Valueat-Risk. Journal of Applied Business and Economics.6(12) 19-28.

Lopez, J.A., (2001). Evaluating the predictive accuracy of volatility models. Journal of Forecasting. 20(29), 87-109.

Luciano, E., P. Semeraro, (2010). Multivariate time changes for Lévy asset models: Characterization and calibration. Journal of Computational and Applied Mathematics 233(25), 1937-1953.

Nilsson, C. (2017). Forecasting Swedish stock market volatility and value-at-risk: A comparison of EWMA and GARCH models, Lunda University.

Palm, F.C. (1996). GARCH models of volatility. Handbook of statistics. 14(3), 209240. 
Sadeghi, H., S. Behboodi, (2016). Using Extreme Value Theory to Estimate Value at Risk (Case Study: Foreign Exchange rate). Asset Management \& Financing 4(2), 77-94.

Salah, H.B., JG De Gooijer, A. Gannoun, M. Ribatet, (2018). Mean-variance and mean-semivariance portfolio selection: a multivariate non-parametric approach. Financial Markets and Portfolio Management 32(12), 419-436.

Socgnia, V.K., D. Wilcox, (2014). A comparison of generalized hyperbolic distribution models for equity returns. Journal of Applied Mathematics.7(12), 1225

Tankov, P., (2010). Financial modeling with Lévy processes. Institute of Mathematics of the Polish Academy of Sciences (IMPAN), Warsaw, 2010, pp.101. ffcel$00665021 \mathrm{f}$

Yildirak, K., C. Ekinci, (2013). A Review of Market Risk Measures and Computation Techniques, Rethinking Valuation and Pricing Models. Elsevier, pp.22(10), 283302.

Zakoian, J., M. (1994). Threshold heteroskedastic models. Journal of Economic Dynamics and Control 18(12), 931-955.

Zhu, B., S. Ye, K. He, J. Chevallier, R. Xie. (2019). Measuring the risk of European carbon market: an empirical mode decomposition-based value at risk approach. Annals of Operations Research. 281(13), 373-395. 
